\title{
Experimental Archaeology on Metals: Learn and Practice to Understand the Sensibility of Metallurgy
}

\author{
Nicolas Gailhard* \\ Department National Center for Scientific Research (CNRS), Sorbonne University, Paris, France
}

Submission: January 15, 2018; Published: May 04, 2018

*Corresponding author: Nicolas Gailhard, 4 bis, avenue de la vigne, domaine de la vigne, 34300 Agde, France, Email: nicogailhard@hotmail.com; info@arkeoservice.com

\begin{abstract}
Experimental archaeology provides a method of research into material culture, in which the work of artisans of the past can be studied in terms of their abilities and their development through practical experience. We believe that this interdisciplinary approach, including experimental and ethnographic data, will be rewarding for all those working on the technological aspects of archaeology. One point will be highlighted, with the example of archaeometallurgy and the use of the senses. This paper explores experimental archaeology's potential as a powerful research method, an effective educational tool and an excellent medium for public outreach.
\end{abstract}

Keywords: Experimental Archaeology; Archaeometallurgy; Metallurgy; Technical Knowledge; Practical Skills; Science Communication; Senses; Furnaces; Workshop; Proximal Development Zone; Savoir-Faire; Abandonment; Protohistoric; Charcoal; Sensibility

\section{Introduction}

The learning process and acquisition of technical knowledge are essential elements to be explained and understood in order to analyze the different stages of copper or iron production in the past. Indeed, this theory that the acquisition of knowledge is achieved by this means is one of the tools we have to feed into our reflection on the work of ancient metallurgy. Experimental archaeological studies bring us a lot of information about the functioning of a workshop and the person attached to it. The study of learning theories can highlight some facts that are behind the organization of the metalworker's workshop. This will allow us to better understand and interpret the archaeological remains of the workshop area.

The theory that the acquisition of knowledge is achieved through a learning process has developed from the work of psychologist Lev Vygotsky. He defines the notion of "proximal development zone" as being halfway between what novices can do alone and what they can only do under the guidance of more experienced specialists [1]. These provide the knowledge that allows beginners to progress and accomplish tasks that they could not carry out without this help. It is through a common effort that novices appropriate the knowledge and techniques of those around them. They avoid the phases of discovery and invention that they would have been faced with without the help of the qualified workers. In a way, there is a practice phase "guided" by more experienced workers facilitating the shared resolution of problems.

\section{Development of Practical Skills (Savoir-Faire)}

We take here the definition of Jacques Pelegrin [2]. Practical Skills is "mental operations and estimates of expectations". It is very important in this context. It does not lend itself easily to systematization or oral transmission. It exists and is acquired mainly through active practice. Indeed, it does not result only from a memorization of learned cases, but rather from an intelligent interpretation of the realized experiments. From these reflections follows a model of learning that highlights four important points

a. Beginners are not perceived as passive actors who receive cultural knowledge instilled by an authority. On the contrary, they must actively and creatively participate in the learning process. It follows that this knowledge is not "transmitted" but rather constituted and continually renewed.

b. The learning environment provides decisive support for the acquisition of knowledge. The familiar context makes it easier for beginners to solve problems.

c. Mutual support between apprentices is an important factor. They help each other according to their respective levels of experience. Sometimes the teacher can also benefit from this assistance in improving their skills.

d. Finally, action is at the heart of the process, while learning is not dissociated from the application. 
Why address these learning theories in the study of ancient technologies such as metallurgy?

Archaeological remains give access to various technological activities, such as metallurgy. These activities are undoubtedly the result of a set of actions that can only be rediscovered by using cross-approaches that go beyond traditional archaeology.

These or other theories, such as those of experimental archaeology for example, should help the archaeologist in this research. We ourselves become apprentice metallurgists in order to understand the operation and to more easily identify the traces left by this technology. The observation and the study of practice "live", the reasoned practice, as proposed by learning techniques or ethno archaeology, constitute one of the bases of the experimental approach.

\section{Experimental Approach in Archaeometallurgy}

Experimentation can make it possible to recover the means of appropriation of thermic transition phenomena in antiquity. A comparison of the attitudes of the current, scientific and the protohistoric craftsman in the field of metallurgy shows all the misunderstandings that can emerge from these two approaches which are such different ways to practice the same technique. Our current approach is to define directly at the heart of the metallurgical process the changes, the reactions that occur there, through a series of measurements, plus chemical and physical experiments. On the other hand, the ancient craftsman was obliged to go through another type of analysis to conduct the melting process: he appealed to his senses and observed the metallurgical phenomenon from the outside and not from the inside, as we can now do. We are therefore obliged to look for other signs in the heart of the reaction.

Andrieux says he uses "a vector of transmission" [3]. Observation of the flame is one of the most often cited vectors for stoking a fire. But other aspects are also to be taken into account, such as the role of water vapour for example. By placing one's hand on the top of a chimney, we learn from it, as it swells (steam release) or it stings $\left(320^{\circ} \mathrm{C}\right.$ is reached, there is no water in the oven). The use of all our senses to bring about a reduction of ore implies a global and synthetic consideration of the elements. We are in a "state of alchemy", and not like today in a "state of chemistry". It is a reversal of the point of view that must be established to judge archaeological witnesses, but also historical ones, as in the ancient texts dealing with metallurgy. The emphasis is always on "scientific truth", "exact observation". Mircea Eliade recalls that "We mean that there were other 'natural sciences' that were not based on quantity and measurement criteria" [4].

An archaeologist who engages in an experimental approach must limit himself to manipulation of one technique. Above all, anachronisms must be avoided both in terms of material design and desired outcomes. It is not a question of copying but of understanding "in situ" the problems encountered by the protohistoric metallurgist. Attention must be paid to the products obtained (both the finished objects and the waste) which are to be compared with the archaeological artefacts. This practice of experimentation necessarily involves a long learning phase where we "have to relearn manual sensitivity while 'silencing 'our knowledge and a priori current" [5].

The relationship with the archaeological remains constant in the experimental process and ensures its real effectiveness. But it is not enough to examine the archaeological documentation to embark on an experiment. This is often a final stage (Abandonment, destruction) and not a stage of use of the archaeological structure. It is therefore necessary to practice a dynamic reading of the vestige, or remains, and always have an argument in movement and action, choose a point of view where archaeological remains are related to each other. But despite all these precautions, it is not enough to use the same materials to reproduce identical shapes such as ovens and their accessories in order to understand the workshop and these occupants. We do not want, by using archaeological experimentation, just to make a reproduction, a copy, but rather we want to learn how we can make metal.

\section{Active Learning with Children, Students or Specialists}

Finally, part of my work is a transmission of knowledge through the concrete practice of ancient technology, for example the first melting of a bronze object, to such different groups as children, students and archaeologists. The first project was conducted in 2010, in Bodrum, Turkey (Figure 1). We made a series of experiments funded by Tübitak (the Scientific and Technological Council of Turkey) in collaboration with several universities and one NGO (Gaziantep University, Dokuz Eylül University, Paris 1 Sorbonne University and the Gümüşlük Akademisi Vakfı). We constructed on this occasion 12 metallurgical furnaces (4 iron ore reduction furnaces, 4 copper ore reduction ones and 4 open fires to make cast bronze.) This involved more than 20 students who made more than 2,000 clay bricks, handling more than $400 \mathrm{~kg}$ of ore and 3 tons of charcoal.

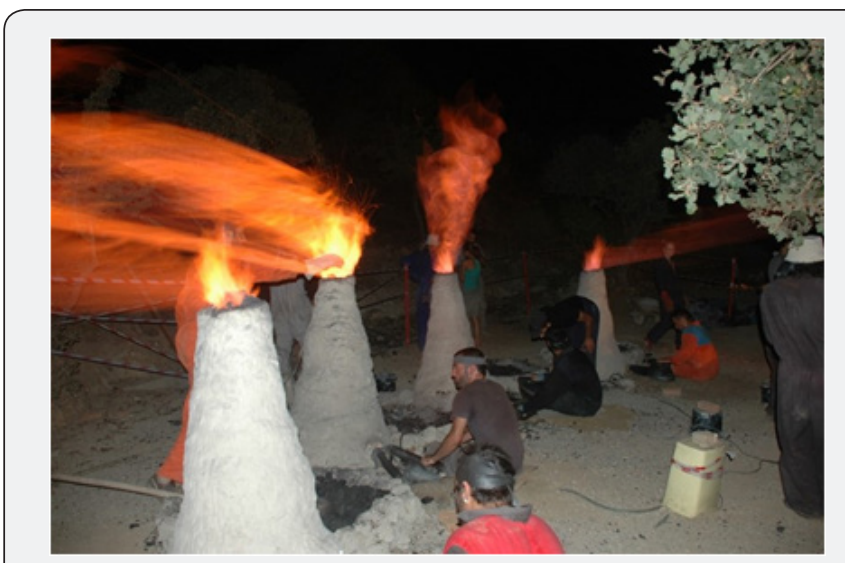

Figure 1: "Days of Experimental Archaeology in Turkey", which took place in 2010 in Gümüşlük and featured the reduction of iron ores with students 
Two other projects were conducted in 2014, in collaboration with Istanbul Technical University Science Center [6]. The first one was called "From metal to object: melting metal as it was done 6000 years ago", and was designed for children of 8-10 years old. The second one, "Art and Knowledge of Metallurgy in Ancient Anatolia" was a series of copper, lead and bronze melting experiments and conferences for specialists. This training allowed the children or archaeologists to express themselves, following the examples of a given material culture. Research conducted in metallurgical experiments with children and students revives the thinking on the study of ancient material culture through techniques and actions, particularly concerning notions about actions and traces. The aim was very clear: to present archaeology and the history of mankind in a sensitive light.

\section{Conclusion}

Through these programs, we learned a lot about ancient material culture, and the techniques of metallurgy, but also about the importance of the transmission of knowledge by practice. It is through this round-trip between archaeological research and experimental practice that we understand better "why test and experiment are not synonymous, "why trying to understand an old technique requires such a long learning phase.

Finally, the active practice of experimental archaeology is a very effective means of transmitting and promoting research carried out. It also allows training and interactions with local experts at different levels (during the excavation for the study of archaeological material, during the experiments themselves, and finally during the study and analysis of the results).

That's why the role of the experimenter is most important, as M-C. Bailly-Maître also points out: "the experimenter, finally, is allowed to cross all this information" archaeological, ethnological, geological and historical.

\section{References}

1. Chaiklin S, Lave J (1993) Understanding in practice: perspectives on activity and context. Cambridge University Press, Cambridge, USA.

2. Pelegrin J (1991) Les savoir-faire : une très longue histoire in Terrain, Carnets du Patrimoine ethnologique. n¹6, mars 1991: 106-113.

3. Andrieux Ph (1991) Lamétallurgie des origines : utilisation de la sensualité comme outil de maîtrise technique. In : Techniques et culture 17(18): 175-193.

4. Eliade M (1991) Cosmologie et alchimie babyloniennes. Arcades Gallimard, première édition 1937.

5. Andrieux Ph (1988) Expérimenter laterre et le feu. In: Dossiers d'Histoire et d'Archéologie 126 : 76-86.

6. Gailhard N (2014) Experimental Archaeology and Science Center in Turkey. A presentation and popularization of Science: Early Bronze Metallurgy, in Arkeolojive Sanat (Journal of Archaeology \& Art) 146: 29-36.

\section{Your next submission with Juniper Publishers} will reach you the below assets

- Quality Editorial service

- Swift Peer Review

- Reprints availability

- E-prints Service

- Manuscript Podcast for convenient understanding

- Global attainment for your research

- Manuscript accessibility in different formats

( Pdf, E-pub, Full Text, Audio)

- Unceasing customer service

Track the below URL for one-step submission https://juniperpublishers.com/online-submission.php 